\title{
Probiotics Dietary Supplementation for Modulating Endocrine and Fertility Microbiota Dysbiosis
}

\author{
Ana López-Moreno 1,2,*(D) and Margarita Aguilera 1,2,3,*(D) \\ 1 Department of Microbiology, Faculty of Pharmacy, University of Granada, Campus of Cartuja, \\ 18071 Granada, Spain \\ 2 Institute of Nutrition and Food Technology “José Mataix", Center of Biomedical Research, \\ University of Granada, 18016 Armilla, Granada, Spain \\ 3 IBS: Instituto de Investigación Biosanitaria ibs., 18012 Granada, Spain \\ * $\quad$ Correspondence: alopezm@ugr.es (A.L.-M.); maguiler@ugr.es (M.A.); Tel.: +34-9-5824-5129 (A.L.-M.)
}

Received: 12 February 2020; Accepted: 9 March 2020; Published: 13 March 2020

\begin{abstract}
Human microbiota seems to play a key role in endocrine and reproductive systems. Fortunately, microbiota reproductive dysbiosis start to be treated by probiotics using typical species from genus Lactobacillus. This work presents the compiled and analysed results from the most up-to-date information from clinical trials regarding microbiota, fertility, probiotics and oral route administration, reviewing open access scientific documents. These studies analyse the clinical impact of probiotics administered on several endocrine disorders' manifestations in women: mastitis; vaginal dysbiosis; pregnancy complication disorders; and polycystic ovary syndrome. In all cases, the clinical modulation achieved by probiotics was evaluated positively through the improvement of specific disease outcomes with the exception of the pregnancy disorders studies, where the sample sizes results were statistically insufficient. High amounts of studies were discarded because no data were provided on specific probiotic strains, doses, impact on the individual autochthon microbiota, or data regarding specific hormonal values modifications and endocrine regulation effects. However, most of the selected studies with probiotics contained no protocolised administration. Therefore, we consider that intervention studies with probiotics might allocate the focus, not only in obtaining a final outcome, but in how to personalise the administration according to the disorder to be palliated.
\end{abstract}

Keywords: probiotics; doses; microbiota; endocrine; fertility; dysbiosis

\section{Introduction}

\subsection{Human Microbiota and Reproductive Impact}

The microbial communities that live in the human body, called microbiota, have an important role in the eubiosis status of each individual [1]. A change in its natural state (dysbiosis) have been shown to contribute to endocrine and metabolic disorders such as bacterial vaginosis [2], polycystic ovary syndrome (PCOS) [3], endometrial hyperplasia and endometriosis [4], and several comorbidities like obesity [5] and diabetes [6].

The vaginal microbiota is particular to each woman, and its role in many facets of reproductive health is increasingly substantiated $[1,7]$. Among all microbial communities that make up the vaginal microbiota, Lactobacillus spp. are the main representative genus for establishing a healthy community [8]. The reasoning behind this physiological impact might be that gastrointestinal microbiota also has a very important active metabolic role in the regulation of the hormonal physiological axis. The GIT microbiota may regulate circulating oestrogens by the secretion of $\beta$-glucuronidase. This enzyme deconjugates oestrogens into their active forms, allowing them to bind their receptors. However, if microbial 
dysbiosis occurs, decreasing bacterial diversity results in a deconjugation decrease and a reduction of circulating oestrogens. This alteration can contribute to the development of hormonal-dependent pathologies $[4,9]$.

\subsection{Dietary Nutritional Supplements: Probiotics and Nutraceuticals}

Probiotics, according to the International Life Sciences Institute (ILSI), WHO, and the International Scientific Association of Probiotics and Prebiotics (ISAPP), are defined as "live microorganisms, which when administered in adequate amounts confer a health benefit on the host" [10].

Nutraceuticals are defined as food product that provide therapeutic or physiological benefits beyond the basic nutritional needs and can be used as dietary supplements. Nutraceuticals are required to be safe and well tolerate, to exhibit less toxicity and secondary side effects compared to drugs used to treat similar symptoms [11-13]. Nutraceuticals and released bioactive compounds by probiotics can be used as therapeutic tools to modulate the human microbiota.

Probiotic strains are selected pseudo-empirically for clinical studies and also based on their previously proven beneficial effects, specific activity or function and safety aspects [14]. Administration of probiotics in clinical studies is also based on the demonstration of safety aspects and stronger probiotic activity [15]. Currently, Health Claims constitute a method for verification of demonstrable beneficial properties of probiotic products through compilation of data such as product characterisation, measurable beneficial effects, and links between the product and the exerted effect and further assessment [16].

Therefore, it is necessary to well identify the microorganisms used in the probiotic formula. There exist high throughput molecular tools (whole genome sequence) and chemotaxonomic techniques (MALDI-TOF) to identify microorganisms used in the chain food, and it is requested to fulfil, first of all, strict taxonomical criteria [17]. Moreover, once it is clarified which strains of probiotics should be recommended, the administration pattern, doses and periods of the intervention should be known before the intake [5].

\subsection{Probiotics Administered in Fertility Dysbiosis}

Today, bacterial vaginosis (BV) is one of the most common forms of vaginal dysbiosis and plays a role in gynaecological complications, such as spontaneous preterm birth, abortion, and endometritis $[18,19]$. BV can be treated by the restauration of vaginal microbiota environment using probiotics. Most commonly used probiotics for modulating fertility dysbiosis include L. reuteri RC-14, L. fermentum, L. gasseri, L. rhamnosus, L. acidophilus, L. crispatus, L. casei, L. salivarius [20-23]. Clinical trials have shown that these probiotics can play a positive role in restoring vaginal microecology and treating BV [24]. Probiotics could also avoid the abuse of antibiotics and further side effects.

\subsection{Type of Administration and Site of Colonisation of Probiotics}

There are different administration routes for probiotics: dermal, rectal, vaginal and oral, the latter being most common. However, for oral administration, probiotics are required to survive low $\mathrm{pH}$ of gut and gastric liquids in the intestine. Therefore, the survival of probiotics in the gastrointestinal tract is usually demonstrated by recovering strains from faecal samples [25,26]. It is also very important to guarantee the transfer to the final site of colonisation, in order to exert the expected clinical effect. Therefore, in the topic of research on fertility, probiotics could reach the vaginal niche by physical transfer or ascendant route, haematogenous route and lymphatic nodes transfer [27]. For the treatment of vulvovaginal infections, probiotics can be administered by the vaginal route in order to control the Lactobacilli recolonisation [25], as a result, these probiotics do not pass through the gastrointestinal tract protecting them from the acidic environment.

We identified this area of research as continuously in progress due to the fact of the growing interest in it by fertility clinicians and patients. Therefore, the main objective of this work was to search, review, extract and present the most up-to-date and relevant scientific evidence from the literature on 
probiotics and its effective modulating role in endocrine disorders related to fertility, using innovative literature methodologies and tools. This review will also improve and unify our knowledge about the administration of probiotics and their effects in this field of clinical research.

\section{Materials and Methods}

\subsection{Search Strategy}

Literature search and review of clinical studies administering specific probiotics strain formula to subjects suffering endocrine and fertility-related disorders were carried out between October 2019 and January 2020 under the stepwise procedure search. The following databases were used: MEDLINE/PubMed [28], Web of Science (Thomson Reuters Scientific), Scopus (Elsevier), and Cochrane Library [29] with search strategies following the search equation and search formula, adapted to each database's tutorials. The combined search approach was performed as follow: (probiotic* AND infertility AND doses); (probiotic * AND microbiota AND fertility); (probiotic * AND microbiota AND infertility); (probiotic * AND “vaginal microbiota" AND infertility); (probiotic * AND endometriosis); (probiotic * AND endometriosis AND fertility); (probiotic * AND endometriosis AND infertility); (probiotic * AND "endometrial microbiota" AND infertility); (probiotic * AND endometrium AND infertility); (probiotic * AND endometrium AND fertility); (probiotic * AND microbiota AND “*vaginal administration"); (probiotic * AND microbiota AND "oral * administration" AND doses); (probiotic * AND ovules); (probiotic * AND reproduct * AND “oral * administration"); (probiotic * AND reproductive AND “*vaginal administration"); (probiotic * AND "Polycystic Ovary Syndrome" AND "oral * administration"); (probiotic * AND "Polycystic Ovary Syndrome").

\subsection{Eligibility Criteria}

To be included in the study, there were four mandatory inclusion criteria: (1) it was published within the last fifteen years (i.e., between 2005 and 2020) and it specified the (2) probiotic strain used, (3) the dose and the (4) time/period of administration. The specific data on population, intervention, comparison and outcome criteria for inclusion are detailed in Table 1.

Table 1. PICO (population, intervention, comparison, outcome) criteria for inclusion of studies.

\begin{tabular}{cc}
\hline Parameters & Inclusion Criteria \\
\hline Population & Human \\
Intervention & Probiotic strains and doses \\
Comparison & Oral probiotics versus placebo \\
Outcome & Improvement on parameters of fertility \\
Setting & Clinical trials (CTs) \\
\hline
\end{tabular}

Exclusion criteria: non-open access documents; non-English-language manuscripts; documents containing no quantitative/biomarker-specific data, e.g., endpoint or outcome; systematic reviews; studies with data results from dysbiosis or not related with fertility; publications without accessibility to the results; publications such as comments, editorials or letters (grey literature).

Each identified eligible article was re-analysed by title and abstract, and the eligible articles were selected for full reading.

The first selection was done based on a term search through title and abstract screening, and the second selection was based on a full-text screening. The first reviewer, A.L.M., conducted the two screening phases, and M.A., a second reviewer supervised the selection. The raw literature search yielded a total of 719 clinical studies with probiotics used to treat metabolic diseases. Furthermore, studies were selected after full-text screening when they met the eligibility criteria. In cases of doubt, articles were also thoroughly analysed based on their full-text content. A PRISMA (preferred reporting 
items for literature search on the topic of interest [30]) flow diagram of the literature search summarises the selection of the studies consisted of two screening phases (Figure 1).

Records identified through database searching $(\mathrm{n}=719)$

PubMed: 112 Web of Science: 339 Scopus: 161 Cochrane: 107

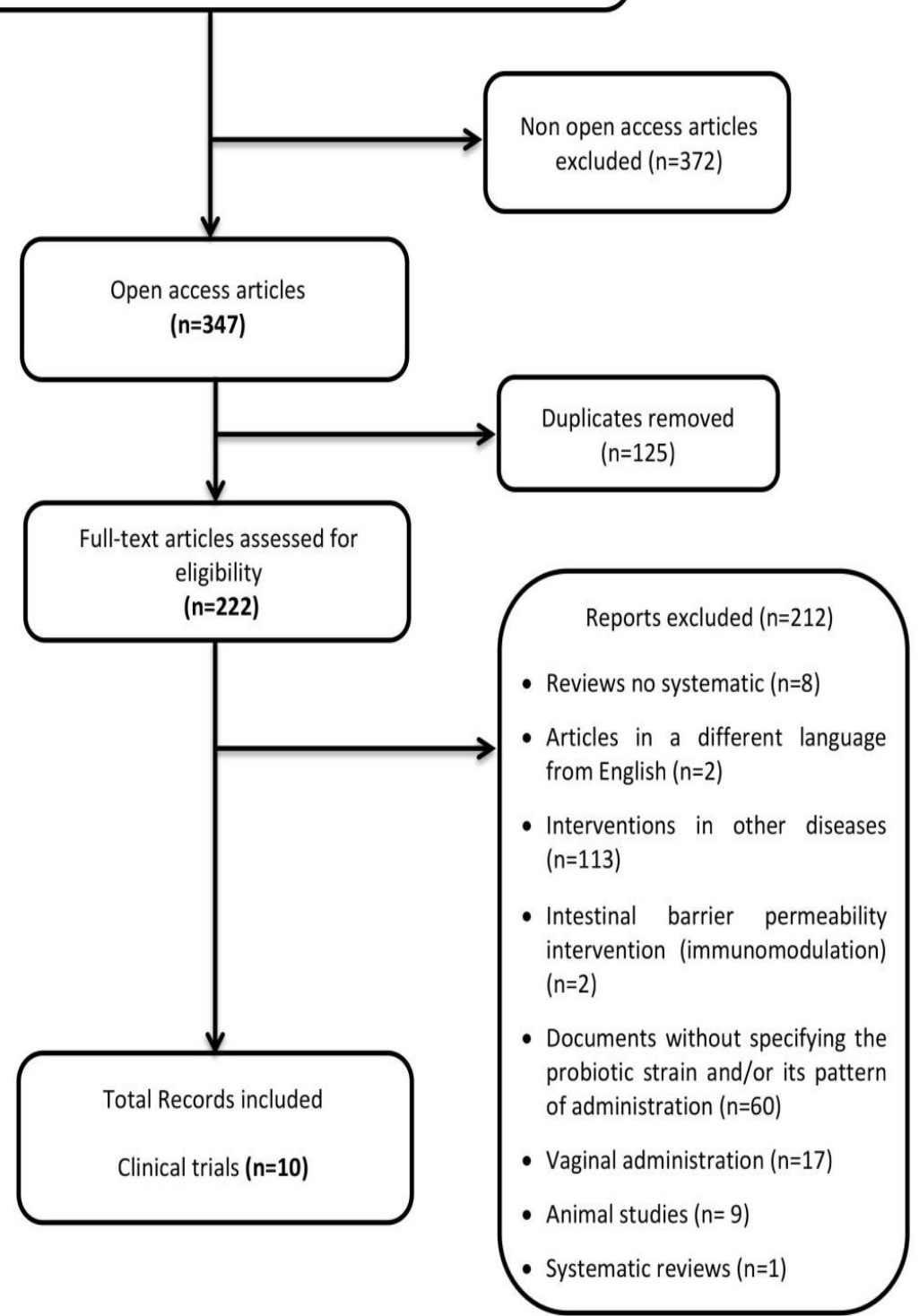

Figure 1. PRISMA flow diagram: preferred reporting items for literature search.

Data Analysis and Extraction

The following data were collected: characteristics of population included: sample size ( $n=$ number of subjects) in the intervention group, gender for clinical trials, specific disease; bacterial probiotic strains used; dose and/or pattern of administration; modification of the clinical parameters included: Nugent score or alterations in fertility-related parameters. Data presentation is summarised in Table 2. Further specifications and key results were retrieved from the CTs in order to visualize the relevance of the probiotics administered and the particular capacities of modulating fertility related dysbiosis. 
Table 2. Summary of the effects of probiotics on human fertility disorders and their clinical outcomes.

\begin{tabular}{|c|c|c|c|c|c|c|}
\hline Reference & $\begin{array}{c}\text { Population } \\
\text { Characteristics Size } \\
(n)\end{array}$ & Probiotic Strain & $\begin{array}{c}\text { Doses and } \\
\text { Administration Pattern }\end{array}$ & $\begin{array}{c}\text { Period of } \\
\text { Intervention (Weeks) }\end{array}$ & Disease & Clinical Parameters Variability \\
\hline Zhang et al. [33] & 14 PCOS patients & $\begin{array}{l}\text { Bifidobacterium lactis } \\
\quad \text { V9 }\end{array}$ & $1 \times 10^{6} \mathrm{CFU} /$ day & 10 & PCOS & $\begin{array}{l}\text { The study showed a potential mechanism by which the } \\
\text { probiotic Bifidobacterium lactis V9 modulates sex hormone } \\
\text { levels in patients with PCOS through the gut-brain axis. }\end{array}$ \\
\hline McMillan et al. [34] & $\begin{array}{l}38 \text { Pregnant women } \\
<36 \text { weeks }\end{array}$ & $\begin{array}{c}\text { Lactobacillus } \\
\text { rhamnosus GR-1 and } \\
\text { Lactobacillus reuteri } \\
\text { RC-14 }\end{array}$ & $1 \times 10^{9} \mathrm{CFU} /$ day & 4 & $\begin{array}{c}\text { Pregnancy associated } \\
\text { disorders }\end{array}$ & $\begin{array}{l}\text { Women in the placebo group were more likely to give birth } \\
\text { preterm. However, the sample size that finished the study } \\
\text { was not large enough to detect significant differences. }\end{array}$ \\
\hline $\begin{array}{l}\text { Krauss-Silva et al. } \\
\text { [18] }\end{array}$ & $\begin{array}{l}4204 \text { Pregnant women } \\
<20 \text { weeks }\end{array}$ & $\begin{array}{c}\text { Lactobacillus } \\
\text { rhamnosus GR-1 and } \\
\text { Lactobacillus reuteri } \\
\text { RC-15 }\end{array}$ & $>2 \times 10^{6} \mathrm{CFU} /$ day & $6-12$ & $\begin{array}{c}\text { Pregnancy associated } \\
\text { disorders }\end{array}$ & $\begin{array}{l}\text { The efficacy of probiotics tested to avoid spontaneous } \\
\text { premature delivery cannot be statistically estimated } \\
\text { because the study sample was insufficient. }\end{array}$ \\
\hline de Andrés et al. [23] & $\begin{array}{l}31 \text { Women (23 with } \\
\text { mastitis) }\end{array}$ & $\begin{array}{l}\text { Lactobacillus salivarius } \\
\text { PS2 }\end{array}$ & $3 \times 10^{9}-3 \times 10^{10} \mathrm{CFU} /$ day & 3 & Mastitis & $\begin{array}{l}\text { The results proved the involvement of modulation of } \\
\text { inflammatory and cell-growth related pathways and genes } \\
\text { in the somatic cells following the intake of } L \text {. salivarius PS2. }\end{array}$ \\
\hline Jiménez et al. [31] & $\begin{array}{l}20 \text { Women with } \\
\text { mastitis }\end{array}$ & $\begin{array}{c}\text { Lactobacillus salivarius } \\
\text { CECT5713 and } \\
\text { Lactobacillus gasseri } \\
\text { CECT5714 }\end{array}$ & $1 \times 10^{10} \mathrm{CFU} /$ day & 4 & Mastitis & $\begin{array}{l}\text { Both probiotics appears to be an efficient alternative for the } \\
\text { treatment of infectious mastitis during lactation. }\end{array}$ \\
\hline Arroyo et al. [21] & $\begin{array}{l}352 \text { Women with } \\
\text { mastitis }\end{array}$ & $\begin{array}{c}\text { Lactobacillus } \\
\text { fermentum CECT5716 } \\
\text { Lactobacillus salivarius } \\
\text { CECT5713 }\end{array}$ & $1 \times 10^{9} \mathrm{CFU} /$ day & 3 & Mastitis & $\begin{array}{l}\text { L. fermentum CECT5716 or L. salivarius CECT5713 seem to } \\
\text { be an efficient alternative to antibiotics for the treatment of } \\
\text { infectious mastitis during lactation. }\end{array}$ \\
\hline Fernández et al. [32] & $\begin{array}{l}108 \text { Healthy pregnant } \\
\text { women }\end{array}$ & $\begin{array}{l}\text { Lactobacillus salivarius } \\
\text { PS2 }\end{array}$ & $1 \times 10^{9} \mathrm{CFU} /$ day & $\sim 8$ & Mastitis-Pregnancy & $\begin{array}{l}\text { Administration of L. salivarius PS2 during late pregnancy } \\
\text { appears to be an efficient method to prevent infectious } \\
\text { mastitis in a susceptible population. }\end{array}$ \\
\hline $\begin{array}{c}\text { Zeber-Lubecka et al. } \\
\text { [37] }\end{array}$ & 39 Preterm infants & $\begin{array}{c}\text { Saccharomyces } \\
\text { boulardii }\end{array}$ & $2 \times 10^{9} \mathrm{CFU} /$ day & 6 & Microbiota dysbiosis & $\begin{array}{l}\text { There were no statistical differences between babies } \\
\text { supplemented with probiotic and without probiotic. }\end{array}$ \\
\hline Anukam et al. [36] & $\begin{array}{l}59 \text { Women with } \\
\text { vaginal dysbiosis }\end{array}$ & $\begin{array}{c}\text { Fluconazol, } \\
\text { Lactobacillus } \\
\text { rhamnosus GR-1 y } \\
\text { Lactobacillus reuteri } \\
\text { RC-14 }\end{array}$ & $5 \times 10^{9} \mathrm{CFU} /$ day & 24 & Vaginal dysbiosis & $\begin{array}{l}\text { Probiotics did not affect the cure rate but did lead to fewer } \\
\text { vulvovaginitis recurrences with its long-term use. }\end{array}$ \\
\hline $\begin{array}{l}\text { Bohbot and Cardot } \\
\quad[35]\end{array}$ & 20 Healthy women & $\begin{array}{l}\text { Lactobacillus casei } \\
\text { variety rhamnosus } \\
\text { (LCR35) }\end{array}$ & $\begin{array}{l}\text { Group 1: } 1 \times 10^{8} \mathrm{CFU} / \text { day } \\
\text { Group 2: } 2 \times 10^{8} \\
\text { CFU/day }\end{array}$ & 4 & Vaginal dysbiosis & $\begin{array}{l}\text { Probiotic decreased the Nugent score in both groups, but it } \\
\text { was slightly more significant in group } 2 \text {. }\end{array}$ \\
\hline
\end{tabular}




\subsection{Risk of Bias (Quality) Assessment}

We (i.e., A.L.M.) independently assessed the risk of bias of the selected documents using the Cohrane collaboration's methodology. A second reviewer (M.A.) was involved in this evaluation thoroughly. Risk of bias was tabulated for each study (Figure 2), and each item evaluated was classified as low risk (-), high risk (+) or unclear risk (?) (Figure 3), according to recommendations described in Chapter 8 of the Cochrane Handbook of Systematic Reviews of Interventions [28]. This analysis and correspondent figures were generated in RevMan 5.3.

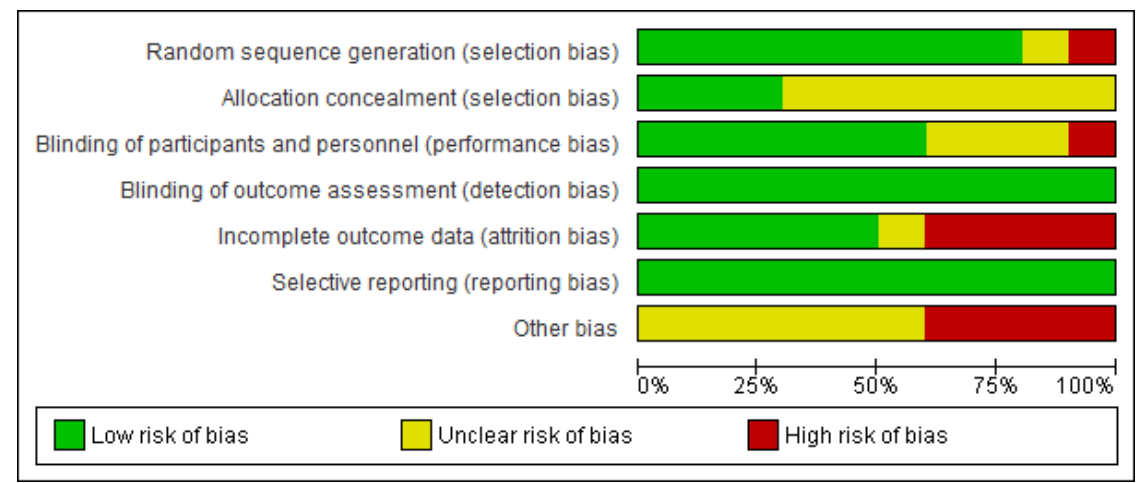

Figure 2. Risk of bias graph: review authors' judgments about each item presented as percentages across all included studies.

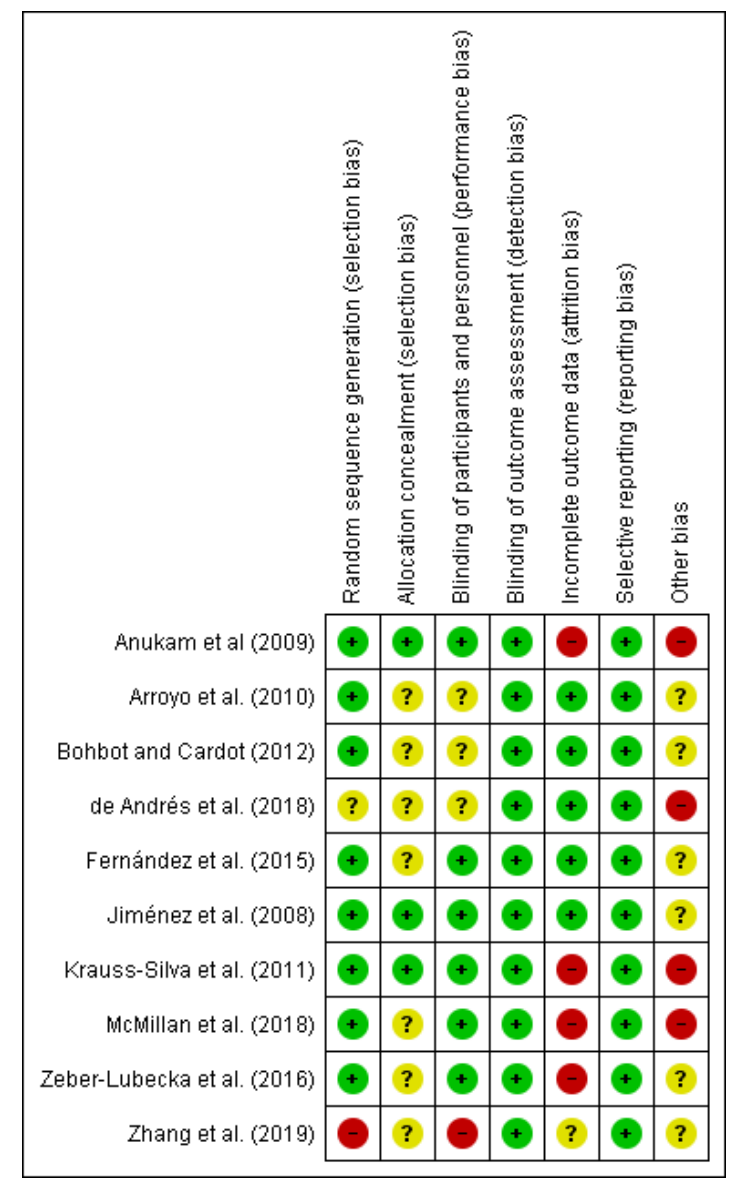

Figure 3. Risk of bias summary: review authors' judgments about each risk of bias item for each included study. 


\section{Results}

The present systematic review focuses on the selection of fully accessible data about probiotics used for modulating dysbiotic microbiota in fertility disorders. We found 222 studies in accordance with our inclusion criteria from a total of 719 documents. Only ten of these chosen studies were clinical trials, and the main results are presented in Table 2. The method applied for selecting the final documents guaranteed the quality of these studies. Moreover, the possibilities to assess the risk of biases of the CT designs, execution and outcomes increased the categorization of the applied quality standards. It gave added value to the evaluated CTs and allowed validating the reviewed results (Figure 2; Figure 3).

The probiotics doses and the duration of interventions varied from $1 \times 10^{6} \mathrm{CFU} /$ day to $3 \times 10^{10}$ CFU/day and from 3 to 24 weeks in the selected clinical trials. None of the probiotics used triggered any safety concerns.

In regard to the disorders and symptoms treated by probiotics, we found 4 articles about women suffering mastitis due to the presence of various causes including hormonal imbalances. All studies showed a significant improvement in the clinical status of the patient groups that received specific strains of Lactobacillus [21,23,31,32]. In the case of PCOS patients, one study administered Bifidobacterium lactis V9 to 14 patients and showed positive modulation capacities of sex hormone levels [33]. Moreover, the controlled administration of probiotics during pregnancy, microbiota disorders allowed us to select only two clinical studies, but the sample size was insufficient to conclude specific modulation capacities [18,34]. Finally, for the treatment of vaginal dysbiosis, there was one study that proved the use of specific probiotics for restoring vaginal microbiota towards normal Nugent score [35] and one study that reduced successfully the recurrence of colonisation by pathogenic bacteria [36].

We further reviewed, extracted and highlighted the relevant information from the selected studies. Therefore, the study carried out by Zhang et al. [33] in PCOS patients revealed the relevance of determining the individual physiological status before administering the probiotics to be tested. Data determinations on microbiota compositional variability, key metabolites (SCFA, TC), gut-brain mediators (Ghrelin, PYY) and sex hormones levels were decisive for the outcome comparisons. These authors also postulated the potential mechanism undergoing the regulation of LH and LH/FSH hormones levels by Bifidobacterium lactis V9 supplementation.

The evaluation of the bacterial probiotics Lactobacillus rhamnosus GR-1 and Lactobacillus reuteri RC-14/15 and their modulation capacities on pregnancy associated problems, such as avoiding preterm birth, were also studied in relation to the individual vaginal dysbiosis status $[18,34]$. Both studies administered differential doses of probiotics $\left(1 \times 10^{9} \mathrm{CFU} /\right.$ day over 4 weeks and $>2 \times 10^{6} \mathrm{CFU} /$ day during 6-12 weeks); however, the results demonstrated the prevention of premature delivery comparing to placebo groups. In any case, the final sample size adhered to the probiotics treatment, and the lack of further experimental assays did not allow for the obtention of robust statistical significance for the probiotic intent-to-treat effects. For similar statistical reasons, there was no possibility to evaluate the differential patterns of microbiota colonisation in preterm infants when administering Saccharomyces boulardii [37].

Probiotics have been used for avoiding mastitis symptoms. At this point, four studies had fulfilled the selection criteria and were reviewed thoroughly. The clinical trial designed by de Andrés et al. [23] applied omics technologies to describe the interindividual variability of gene expression changes in somatic cells and blood leukocytes by the action of Lactobacillus salivarius PS2. The results demonstrated its modulating role in inflammatory and cell-grow only in the breast milk somatic cells. The results indicated that clinical interventions would take advantages from personalized use of probiotics therapy due to the individual response variability linked to the complexity of gene expressions. The study from Jiménez et al. [31] administered Lactobacillus salivarius CECT5713 and Lactobacillus gasseri CECT5714 to the probiotic group versus placebo to the control group. For later analysis of the progression of mastitis, they counted and identified bacteria in the milk samples, finding no clinical signs of mastitis in the probiotic group at day 14, but mastitis persisted on the placebo group. Also, at day 
30 probiotic group showed a lower staphylococcal count than the control group $\left(10^{2}-10^{3} \mathrm{CFU} / \mathrm{mL}\right.$; $10^{4}-10^{5} \mathrm{CFU} / \mathrm{mL}$, respectively). Both probiotic strains administered together appeared to be efficient for treating infectious mastitis during lactation. In the case of Arroyo et al. [21], they administered L. fermentum CECT5716 and L. salivarius CECT5713 separately to two probiotic groups and showed at day 21 almost $1 \log 10 \mathrm{CFU} / \mathrm{mL}$ staphylococcal lower count in probiotic groups than antibiotic group. Also, probiotics can be administered during pregnancy for the mastitis prevention. Fernández et al. [32] administered L. salivarius PS2 during late pregnancy, and only $25 \%$ of women in the probiotic group developed the disease in contrast with $57 \%$ of women in the control group, being efficient to prevent infectious mastitis in a susceptible population.

Vaginal dysbiosis interventional studies with probiotics also showed similar clinical improvements, such as less vulvovaginitis recurrences, but without modifying cure rates. Moreover, oral probiotics supplementations decreased Nugent score [35,36]. Oral Lactobacillus probiotics tested were able to successfully resist the conditions of gastric tract for colonizing temporarily the vaginal area. In addition, they showed high level of safety according to the administered doses and treatment patterns.

In addition, nine related studies were identified and selected from animal clinical studies (Supplementary Materials Table S1) and one systematic review (Supplementary Materials Table S2) from human clinical data that could both support several hypotheses of probiotics colonisation, transfer route and clinical effects. These studies could also give some added value for comparing probiotic capacities of modulation during the intervention. Transversally, we found three interesting articles about sperm quality with three different outpoints: a decrease in the quality [38], zero negative effects [39] and an increase in the quality [40] with different probiotics administration pathways. The systematic review selected for comparison of the results analysed three articles focused on treatments of vaginal dysbiosis, and the achievement of reduction of colonisation by pathogenic bacteria [20].

\section{Discussion}

In recent years, the relevance of probiotics and their beneficial effects through modulating microbiota in several disorders have been extended within the clinicians. Moreover, probiotic supplements and their active compounds formulated as nutraceuticals have become better accepted for general consumers and potential patients [24,41,42]. Probiotics have also shown scientific evidence for their positive role in fertility disorders and for hormonal imbalances. This could be due to the increasing evidence of abundance and impact of microorganisms on the reproductive tract, so it is pertinent to deeply explore the use of probiotics in the context of endocrine and reproductive health [1].

There are an increasing number of research studies proving the beneficial effects of probiotic oral supplementation. Moreover, at this time, there is unequivocal evidence of a direct beneficial effect on reproductive health clinical outcomes. All the same, oral administration of Lactobacillus rhamnosus GR-1 and Lactobacillus fermentum RC-14 have been shown to restore healthy vaginal microbiota in up to $82 \%$ of women with previous vaginal dysbiosis, specifically an increase in Lactobacillus species [43]. In addition, a recent study examined the relationship between the composition of the endometrial microbiota and infertility, showing $30 \%$ to $71 \%$ of infertile women have endometriosis [44]. Interestingly, Moreno et al. [45] found also a correlation between adverse pregnancy outcomes and endometrial microbiota's lower colonisation in Lactobacillus species, concluding by associating this fact with the negative effects, poor reproductive outcomes, implantation failure and pregnancy loss [46-48].

The presence of bacterial microbiota in the placenta during pregnancy is not well supported. There are still controversial studies regarding human uterine and placenta microbiome and the impact on pregnancy and foetus [49-52]. Moreover, establishment and maintenance of placental integrity and function are critical to foetal growth, development and survival [53]. Also, the presence of ruptured membranes causes bacterial infections, $70 \%$ on average, which elicit a maternal inflammatory response [54]. Before the omics technologies era, the sterile human foetal environment (placenta, foetus and amniotic fluid) and the acquisition of the microbiota during and after delivery was an accepted dogma [49]. 
Recently, studies using sequencing-based methods suggested the presence of bacterial communities in the placenta. Aagaard et al. [51] characterized a unique placental microbiome niche composed of non-pathogenic commensal microbiota. Prince et al. [52] found a relationship among the alterations of the placental microbiota with the severity of chorioamnionitis. Both studies [51,52] showed a lower abundance of the microbial community in the placenta analyses. Conversely, recent studies identifying this low abundance do so with potential false-positive results, due to the fact of an insufficient detection limit using sequencing-based methods [49] or reagent and laboratory contamination $[55,56]$.

As previously commented, formula supplementations containing probiotic strains are increasing as dietary and therapeutic products [57]. Regardless of the scarce data on probiotic strains, many authors only report on genus and species data [58]. However, it is well-known that the biological effects of probiotics are strain-specific dependent [59]. The effects of one strain cannot be extrapolated to another strain. Accordingly, the specific benefits of the probiotic strain highlight the need to include a complete identification of the probiotic to the strain level [60]. In any cases, it is required to carry out more studies and test the beneficial impact of probiotics, because in many cases, there are only one clinical trial that supported their claims [58]. In addition, many other parameters need to be harmonized, such as the pattern of administration or target population, since it has been seen that the beneficial effect of a probiotic in a population may not be adequate for another population, even causing potential adverse effects $[57,61]$.

In summary, the collection of relevant results pursued in the present review were the verification of the availability of complete key clinical data during the accomplishment of probiotic fertility dysbiosis interventions regarding the following relevant aspects: selection of probiotic strain, doses, administration pattern and key endpoints modulation capacities. Interestingly, from a total of 719 studies initially gathered, only ten clinical trials fulfilled the inclusion criteria (Figure 1). In contrast, there were an enormous amount of clinical studies without these specifications (see Supplementary Materials).

Most of the probiotics used were Lactobacillus species, due to the fact of their natural predominance in these colonizing sites [62] and other manufacturing and technological concerns, e.g., anaerobiosis [63]. Similarly, specific probiotic strains of Lactobacillus were also selected for vaginal dysbiosis studies in human clinical trials (Table 2) and animal studies (Supplementary Materials Table S1). Some species of Lactobacillus, L. acidophilus, L. crispatus, L. plantarum, L. fermentum and L. gasseri makeup the predominant normal microbiota of the genitourinary and gastrointestinal (GI) tract of healthy individuals, and its effectiveness in maintaining the normal $\mathrm{pH}$ of the vagina and preventing genital infections has been well demonstrated [64,65]. Within the genus Lactobacillus, as described above, L. gasseri has been widely used as a probiotic. In the study of Itoh et al. [66], the administration of L. gasseri OLL2809 heat-killed achieved the suppression of the development of endometriosis in mice. The selection of this strain was based on its immunostimulatory activity [67,68]. Qin et al. [69] compared the effects of Lactobacillus rhamnosus CICC6141 and Lactobacillus casei BL23 on Danio rerio and, either separately or in combination, they found stimulation in parameters of the reproductive process. The process of probiotic selection was done according to the level of adhesion to the epithelial gut capacities [70].

Besides, Lactobacillus have been used in studies of mastitis or colonisation of the mammary gland (MG), as in the Treven et al. [71] study, in which L. gasseri K7 and L. rhamnosus GG can modulate the bacterial composition of the mammary gland. These bacteria were selected by the previous demonstration of modulation of MG colonisation capacities and, consequently, colonisation of the infant's gut [72,73]. However, in the case of human clinical trials of mastitis, the predominant probiotic strains used are Lactobacillus salivarius PS2, L. salivarius CECT5713, L. gasseri CECT5714, L. fermentum CECT5716 [21-23,31,32], also the doses and period of administration were quite similar (3-4 weeks), with the exception of Fernández et al. [32] in which study's period of administration lasted about 8 weeks. In all studies, the strains administered seem to be an efficient method for the treatment of mastitis and other hormonal imbalances triggering infections, as alternatives to antibiotics. Finally, probiotics of the genus Lactobacillus have also been used to treat vaginal dysbiosis. Specifically, 
L. rhamnosus GR-1, L. reuteri RC-14, L. casei LCR35, L. fermentum RC-14, L. fermentum RC-15 and L. fermentum RC-16 [20,35,36] strains, thus improving the microbiota vaginal to normal or intermediate Nugent scores and reducing recurrence of pathogen colonisation.

Exceptionally, despite the common use of the genera Lactobacillus, also in animal studies, dos Santos et al. [38] administered Bacillus subtilis to roosters, due to the fact of its use as a dietary supplement to prevent gastrointestinal disorders and enhance growth performance [74]; however, no effects or lack of conclusive information were found regarding the fertility assays. Conversely, few species of Bacillus are considered suitable for commercialized oral dietary supplements. They have been commonly approved for their history of safe use (Bacillus subtilis (DSM10), Bacillus clausii (DSM 8716), Bacillus coagulans (DSM 1), Bacillus amyloliquefaciens (DSM 7) [75]. Moreover, Valcarce et al. [40] studied in animal models the effects of Lactobacillus rhamnosus CECT8361 and Bifidobacterium longum CECT7347 on sperm quality finding an improvement of the parameters, these probiotics were selected because of its antioxidant and anti-inflammatory activities [40,76]. On the other hand, probiotics of the genus Bifidobacterium have been used for the treatment of PCOS, specifically the strain Bifidobacterium lactis V9, previously tested by Zhang et al. [33] and selected for exhibiting excellent probiotic characteristics.

Some studies have been conducted to prove the capacity of orally administered Lactobacilli to be transferred from the intestinal tract to the vagina and positively colonize and influence vaginal health $[20,35]$. Comparatively, despite vaginal administration allowed a direct and targeted colonisation action of the probiotics for restoring unhealthy vaginal microbiota, other many studies defended the thesis that oral administration is more effective against bacterial vaginosis, and less aggressive for established microbiota, and, in summary, it constitutes a natural route of colonisation [77].

Finally, most of the clinical trials reviewed reported on the safety aspects of the prescribed probiotics during the interventions. None of the studies showed data on side or adverse effects triggered by the probiotics administered. All probiotics used should be innocuous by history of safe use and proven safety features [78] for commercial products marketed [79]. The commercial probiotic species used should have the qualifications QPS (qualified presumption of safety) [80] or GRAS (generally recognized as safe) [81].

\section{Conclusions}

The clinical modulation achieved by specific doses of oral administered probiotics was evaluated positively through the improvement of the specific hormonal- and fertility-related disease outcomes with the exception of two pregnancy disorder studies. However, most of the selected studies contained no data harmonised on the probiotic administration, and it made it difficult to clinically protocolised the probiotic modulation capacities. Therefore, we consider that future interventional studies with probiotics might allocate the focus, not only in obtaining a final outcome, but in how to personalise the administration according to the disorder to be palliated.

Supplementary Materials: The following are available online at http://www.mdpi.com/2072-6643/12/3/757/s1, Table S1. Summary of the effects of probiotics on animal's fertility disorders and their outcomes; Table S2. Summary of the effects of probiotics founds on systematics reviews.

Author Contributions: Conceptualization, M.A.; methodology, A.L.-M. and M.A.; writing-original draft preparation, A.L.-M.; review and editing, A.L.-M. and M.A. Both authors have read and agreed to the published version of the manuscript. All authors have read and agreed to the published version of the manuscript.

Funding: This research received no direct external funding. A.L.M. was granted with the IniciaTC programme-OTRI-UGR in collaboration with Fertypharm S.L.

Acknowledgments: Ana López Moreno and Margarita Aguilera are part of the BIO-190 Research Group. They are also part of "UGR Plan Propio de Investigación 2019-2020.

Conflicts of Interest: The authors declare no conflict of interest. 


\section{References}

1. García-Velasco, J.; Menabrito, M.; Catalán, I. What fertility specialists should know about the vaginal microbiome: A review. Reprod. BioMed. Online 2017, 35, 103-112. [CrossRef] [PubMed]

2. Vazquez, F.; Fernández-Blázquez, A.; García, B. Vaginosis. Microbiota vaginal. Enferm. Infecc. Microbiol. Clin. 2019, 37, 592-601. [CrossRef] [PubMed]

3. Torres, P.; Siakowska, M.; Banaszewska, B.; Pawelczyk, L.; Duleba, A.; Kelley, S.; Thackray, V. Gut Microbial Diversity in Women With Polycystic Ovary Syndrome Correlates With Hyperandrogenism. J. Clin. Endocrinol. Metab. 2018, 103, 1502-1511. [CrossRef] [PubMed]

4. Baker, J.; Al-Nakkash, L.; Herbst-Kralovetz, M. Estrogen-gut microbiome axis: Physiological and clinical implications. Maturitas 2017, 103, 45-53. [CrossRef]

5. Fontané, L.; Benaiges, D.; Goday, A.; Llauradó, G.; Pedro-Botet, J. Influencia de la microbiota y de los probióticos en la obesidad. Clin. Investig. Arterioscler. 2018, 30, 271-279. [CrossRef]

6. Rondanelli, M.; Faliva, M.; Perna, S.; Giacosa, A.; Peroni, G.; Castellazzi, A. Using probiotics in clinical practice: Where are we now? A review of existing meta-analyses. Gut Microbes 2017, 8, 521-543. [CrossRef]

7. Anahtar, M.; Gootenberg, D.; Mitchell, C.; Kwon, D. Cervicovaginal Microbiota and Reproductive Health: The Virtue of Simplicity. Cell Host Microbe 2018, 23, 159-168. [CrossRef]

8. Pramanick, R.; Mayadeo, N.; Warke, H.; Begum, S.; Aich, P.; Aranha, C. Vaginal microbiota of asymptomatic bacterial vaginosis and vulvovaginal candidiasis: Are they different from normal microbiota? Microb. Pathog. 2019, 134, 103599. [CrossRef]

9. Ata, B.; Yildiz, S.; Turkgeldi, E.; Brocal, V.; Dinleyici, E.; Moya, A.; Urman, B. The Endobiota Study: Comparison of Vaginal, Cervical and Gut Microbiota between Women with Stage 3/4 Endometriosis and Healthy Controls. Sci. Rep. 2019, 9, 2204. [CrossRef]

10. Hill, C.; Guarner, F.; Reid, G.; Gibson, G.R.; Merenstein, D.J.; Pot, B.; Morelli, L.; Canani, R.B.; Flint, H.J.; Salminen, S.; et al. Expert consensus document. The International Scientific Association for Probiotics and Prebiotics consensus statement on the scope and appropriate use of the term probiotic. Nat. Rev. Gastroenterol. Hepatol. 2014, 11, 506-514. [CrossRef]

11. Bernal, J.; Mendiola, J.; Ibáñez, E.; Cifuentes, A. Advanced analysis of nutraceuticals. J. Pharm. Biomed. Anal. 2011, 55, 758-774. [CrossRef]

12. Ting, Y.; Jiang, Y.; Ho, C.; Huang, Q. Common delivery systems for enhancing in vivo bioavailability and biological efficacy of nutraceuticals. J. Funct. Foods 2014, 7, 112-128. [CrossRef]

13. Sharma, M.; Dwivedi, P.; Singh Rawat, A.; Dwivedi, A. Nutrition nutraceuticals: A proactive approach for healthcare. Nutraceuticals 2016, 4, 79-116.

14. Kothari, D.; Patel, S.; Kim, S. Probiotic supplements might not be universally-effective and safe: A review. Biomed. Pharmacother. 2019, 111, 537-547. [CrossRef] [PubMed]

15. Lara-Villoslada, F.; Sierra, S.; Díaz-Ropero, M.; Olivares, M.; Xaus, J. Safety Assessment of the Human Milk-Isolated Probiotic Lactobacillus salivarius CECT5713. J. Dairy Sci. 2007, 90, 3583-3589. [CrossRef] [PubMed]

16. EFSA NDA Panel on Dietetic Products, Nutrition and Allergies. General scientific guidance for stakeholders on health claim applications. EFSA J. 2016, 14, 4367. [CrossRef]

17. de Benito, A.; Ibáñez, C.; Moncho, W.; Martínez, D.; Vettorazzi, A.; de Cerain, A. Database on the taxonomical characterisation and potential toxigenic capacities of microorganisms used for the industrial production of food enzymes and feed additives, which do not have a recommendation for Qualified Presumption of Safety. EFSA Supporting Publ. 2017, 14. [CrossRef]

18. Krauss-Silva, L.; Moreira, M.; Alves, M.; Braga, A.; Camacho, K.; Batista, M.; Almada-Horta, A.; Rebello, M.R.; Guerra, F. A randomised controlled trial of probiotics for the prevention of spontaneous preterm delivery associated with bacterial vaginosis: Preliminary results. Trials 2011, 12, 239. [CrossRef]

19. Li, C.; Wang, T.; Li, Y.; Zhang, T.; Wang, Q.; He, J.; Wang, L.; Li, L.; Yang, N.; Fang, Y. Probiotics for the treatment of women with bacterial vaginosis: A systematic review and meta-analysis of randomized clinical trials. Eur. J. Pharmacol. 2019, 864, 172660. [CrossRef]

20. Falagas, M.; Betsi, G.; Athanasiou, S. Probiotics for the treatment of women with bacterial vaginosis. Clin. Microbiol. Infect. 2007, 13, 657-664. [CrossRef] 
21. Arroyo, R.; Martín, V.; Maldonado, A.; Jiménez, E.; Fernández, L.; Rodríguez, J. Treatment of Infectious Mastitis during Lactation: Antibiotics versus Oral Administration of Lactobacilli Isolated from Breast Milk. Clin. Infect. Dis. 2010, 50, 1551-1558. [CrossRef] [PubMed]

22. Borges, S.; Silva, J.; Teixeira, P. The role of lactobacilli and probiotics in maintaining vaginal health. Arch. Gynecol. Obstet. 2014, 289, 479-489. [CrossRef] [PubMed]

23. de Andrés, J.; Jiménez, E.; Espinosa-Martos, I.; Rodríguez, J.; García-Conesa, M. An Exploratory Search for Potential Molecular Targets Responsive to the Probiotic Lactobacillus salivarius PS2 in Women With Mastitis: Gene Expression Profiling vs. Interindividual Variability. Front. Microbiol. 2018, 9, 2166. [CrossRef] [PubMed]

24. Homayouni, A.; Bastani, P.; Ziyadi, S.; Mohammad-Alizadeh-Charandabi, S.; Ghalibaf, M.; Mortazavian, A.; Mehrabany, E. Effects of Probiotics on the Recurrence of Bacterial Vaginosis. J. Low. Genit. Tract Dis. 2014, 18, 79-86. [CrossRef] [PubMed]

25. Mombelli, B.; Gismondo, M. The use of probiotics in medical practice. Int. J. Antimicrob. Agents 2000, 16, 531-536. [CrossRef]

26. Gardiner, G.; Heinemann, C.; Baroja, M.; Bruce, A.; Beuerman, D.; Madrenas, J.; Reid, G. Oral administration of the probiotic combination Lactobacillus rhamnosus GR-1 and L. fermentum RC-14 for human intestinal applications. Int. Dairy J. 2002, 12, 191-196. [CrossRef]

27. Albillos, A.; de Gottardi, A.; Rescigno, M. The gut-liver axis in liver disease: Pathophysiological basis for therapy. J. Hepatol. 2020, 72, 558-577. [CrossRef]

28. Canese, K. An Updated PubMed Is on Its Way. NLM Tech. Bull. 2019, 427. Available online: https: //www.nlm.nih.gov/pubs/techbull/ma19/ma19_pubmed_update.html (accessed on 13 March 2020).

29. Higgins, J.P.; Altman, D.G.; Sterne, J. Chapter 8. In Cochrane Handbook for Systematic Reviews of Interventions; Version 5.1.0.; Higgins, J.P., Green, S., Eds.; The Cochrane Collaboration: London, UK, 2011.

30. Moher, D.; Liberati, A.; Tetzlaff, J.; Altman, D. Preferred Reporting Items for Systematic Reviews and Meta-Analyses: The PRISMA Statement. PLoS Med. 2009, 6, e1000097. [CrossRef]

31. Jiménez, E.; Fernández, L.; Maldonado, A.; Martin, R.; Olivares, M.; Xaus, J.; Rodriguez, J.M. Oral Administration of Lactobacillus Strains Isolated from Breast Milk as an Alternative for the Treatment of Infectious Mastitis during Lactation. Appl. Environ. Microbiol. 2008, 74, 4650-4655. [CrossRef]

32. Fernández, L.; Cárdenas, N.; Arroyo, R.; Manzano, S.; Jiménez, E.; Martín, V.; Rodriguez, J.M. Prevention of Infectious Mastitis by Oral Administration of Lactobacillus salivarius PS2 During Late Pregnancy. Clin Infect. Dis. 2015, 62, 568-573. [CrossRef] [PubMed]

33. Zhang, J.; Sun, Z.; Jiang, S.; Bai, X.; Ma, C.; Peng, Q.; Chen, K.; Chang, H.; Fang, T.; Zhang, H. Probiotic Bifidobacterium lactis V9 Regulates the Secretion of Sex Hormones in Polycystic Ovary Syndrome Patients through the Gut-Brain Axis. mSystems 2019, 4, e00017-e00019. [CrossRef] [PubMed]

34. McMillan, A.; Rulisa, S.; Gloor, G.; Macklaim, J.; Sumarah, M.; Reid, G. Pilot assessment of probiotics for pregnant women in Rwanda. PLoS ONE 2018, 13, e0195081. [CrossRef] [PubMed]

35. Bohbot, J.; Cardot, J. Vaginal Impact of the Oral Administration of Total Freeze-Dried Culture of LCR 35 in Healthy Women. Infect. Dis. Obstet. Gynecol. 2012, 2012, 503648. [CrossRef] [PubMed]

36. Anukam, K.; Duru, M.; Eze, C.; Egharevba, J.; Aiyebelehin, A.; Bruce, A.; Reid, G. Oral use of probiotics as an adjunctive therapy to fluconazole in the treatment of yeast vaginitis: A study of Nigerian women in an outdoor clinic. Microb. Ecol. Health Dis. 2009, 21, 72-77.

37. Zeber-Lubecka, N.; Kulecka, M.; Ambrozkiewicz, F.; Paziewska, A.; Lechowicz, M.; Konopka, E.; Majewska, U.; Borszewska-Kornacka, M.; Mikula, M.; Cukrowska, B.; et al. Effect of Saccharomyces boulardii and Mode of Delivery on the Early Development of the Gut Microbial Community in Preterm Infants. PLoS ONE 2016, 11, e0150306. [CrossRef]

38. Kiess, A.; Hirai, J.; Triplett, M.; Parker, H.; McDaniel, C. Impact of oral Lactobacillus acidophilus gavage on rooster seminal and cloacal Lactobacilli concentrations. Poult. Sci. 2016, 95, 1934-1938. [CrossRef]

39. dos Santos, M.; Ramachandran, R.; Kiess, A.; Wamsley, K.; McDaniel, C. Impact of in vitro inoculation and dietary supplementation with Bacillus subtilis on sperm quality of aged White Leghorn roosters. J. Appl. Poult. Res. 2018, 27, 304-315. [CrossRef]

40. Valcarce, D.; Riesco, M.; Martínez-Vázquez, J.; Robles, V. Diet Supplemented with Antioxidant and Anti-Inflammatory Probiotics Improves Sperm Quality after Only One Spermatogenic Cycle in Zebrafish Model. Nutrients 2019, 11, 843. [CrossRef] 
41. Verna, E.; Lucak, S. Use of probiotics in gastrointestinal disorders: What to recommend? Therap. Adv. Gastroenterol. 2010, 3, 307-319. [CrossRef]

42. Falcinelli, S.; Rodiles, A.; Hatef, A.; Picchietti, S.; Cossignani, L.; Merrifield, D.; Unniappan, S.; Carnevali, O. Dietary lipid content reorganizes gut microbiota and probiotic L. rhamnosus attenuates obesity and enhances catabolic hormonal milieu in zebrafish. Sci. Rep. 2017, 7, 5512. [CrossRef] [PubMed]

43. Reid, G.; Beuerman, D.; Heinemann, C.; Bruce, A. Probiotic Lactobacillus dose required to restore and maintain a normal vaginal flora. FEMS Immunol. Med. Microbiol. 2001, 32,37-41. [CrossRef] [PubMed]

44. Halis, G.; Arici, A. Endometriosis and Inflammation in Infertility. Ann. N. Y. Acad. Sci. 2004, 1034, $300-315$. [CrossRef] [PubMed]

45. Moreno, I.; Codoñer, F.; Vilella, F.; Valbuena, D.; Martinez-Blanch, J.; Jiménez-Almazán, J.; Alonso, R.; Alama, P.; Remohi, J.; Pellicer, A.; et al. Evidence that the endometrial microbiota has an effect on implantation success or failure. Am. J. Obstet. Gynecol. 2016, 215, 684-703. [CrossRef]

46. Ravel, J.; Gajer, P.; Abdo, Z.; Schneider, G.; Koenig, S.; McCulle, S.; Karlebach, S.; Gorle, R.; Russell, J.; Tacket, C.O.; et al. Vaginal microbiome of reproductive-age women. Proc. Natl. Acad. Sci. USA 2010, 108, 4680-4687. [CrossRef]

47. Romero, R.; Hassan, S.; Gajer, P.; Tarca, A.; Fadrosh, D.; Bieda, J.; Chaemsaithong, P.; Miranda, J.; Chaiworapongsa, T.; Ravel, J. The vaginal microbiota of pregnant women who subsequently have spontaneous preterm labor and delivery and those with a normal delivery at term. Microbiome 2014, 2, 18. [CrossRef]

48. Romero, R.; Chaiworapongsa, T.; Kuivaniemi, H.; Tromp, G. Bacterial vaginosis, the inflammatory response and the risk of preterm birth: A role for genetic epidemiology in the prevention of preterm birth. Am. J. Obstet. Gynecol. 2004, 190, 1509-1519. [CrossRef]

49. Perez-Muñoz, M.; Arrieta, M.; Ramer-Tait, A.; Walter, J. A critical assessment of the sterile womb and in utero colonisation hypotheses: Implications for research on the pioneer infant microbiome. Microbiome 2017, 5, 48. [CrossRef]

50. de Goffau, M.; Lager, S.; Sovio, U.; Gaccioli, F.; Cook, E.; Peacock, S.; Parkhill, J.; Charnock-Jones, D.S.; Smith, G.C.S. Human placenta has no microbiome but can contain potential pathogens. Nature 2019, 572, 329-334. [CrossRef]

51. Aagaard, K.; Ma, J.; Antony, K.M.; Ganu, R.; Petrosino, J.; Versalovic, J. The placenta harbors a unique microbiome. Sci. Transl. Med. 2014, 6, 237ra65. [CrossRef]

52. Prince, A.; Ma, J.; Kannan, P.; Alvarez, M.; Gisslen, T.; Harris, R.; Sweeney, E.; Knox, C.; Lambers, D.; Jobe, A.; et al. The placental membrane microbiome is altered among subjects with spontaneous preterm birth with and without chorioamnionitis. Am. J. Obstet. Gynecol. 2016, 214, e1-e627. [CrossRef] [PubMed]

53. Sood, R.; Zehnder, J.; Druzin, M.; Brown, P. Gene expression patterns in human placenta. Proc. Natl. Acad. Sci. USA 2006, 103, 5478-5483. [CrossRef] [PubMed]

54. Romero, R.; Gómez-López, N.; Kusanovic, J.P.; Pacora, P.; Panaitescu, B.; Erez, O.; Yoon, B.H. Clinical Chorioamnionitis at Term: New Insights into the Etiology, Microbiology, and the Fetal, Maternal and Amniotic Cavity Inflammatory Responses. Nogyogy. Es Szulesz. Tovabbk. Szle. 2018, 20, 103-112.

55. Salter, S.J.; Cox, M.J.; Turek, E.M.; Calus, S.T.; Cookson, W.O.; Moffatt, M.F.; Turner, P.; Parkhill, J.; Loman, N.J.; Walker, A.W. Reagent and laboratory contamination can critically impact sequence-based microbiome analyses. BMC Boil. 2014, 12, 87. [CrossRef] [PubMed]

56. de Goffau, M.; Lager, S.; Salter, S.; Wagner, J.; Kronbichler, A.; Charnock-Jones, D.; Peacock, S.J.; Smith, G.C.S.; Parkhill, J. Recognizing the reagent microbiome. Nat. Microbiol. 2018, 3, 851-853. [CrossRef] [PubMed]

57. Rijkers, G.; Bengmark, S.; Enck, P.; Haller, D.; Herz, U.; Kalliomaki, M.; Kudo, S.; Lenoir-Wijnkoop, I.; Mercenier, A.; Myllyluoma, E.; et al. Guidance for Substantiating the Evidence for Beneficial Effects of Probiotics: Current Status and Recommendations for Future Research. J. Nutr. 2010, 140, 671S-676S. [CrossRef] [PubMed]

58. McFarland, L. Use of probiotics to correct dysbiosis of normal microbiota following disease or disruptive events: A systematic review. BMJ Open 2014, 4, e005047. [CrossRef]

59. Azaïs-Braesco, V.; Bresson, J.; Guarner, F.; Corthier, G. Not all lactic acid bacteria are probiotics, but some are. Br. J. Nutr. 2010, 103, 1079-1081. [CrossRef]

60. Rijkers, G.; de Vos, W.; Brummer, R.; Morelli, L.; Corthier, G.; Marteau, P. Health benefits and health claims of probiotics: Bridging science and marketing. Br. J. Nutr. 2011, 106, 1291-1296. [CrossRef] 
61. Kumar, H.; Salminen, S.; Verhagen, H.; Rowland, I.; Heimbach, J.; Bañares, S.; Young, T.; Nomoto, K.; Lalonde, M. Novel probiotics and prebiotics: Road to the market. Curr. Opin. Biotechnol. 2015, 32, 99-103. [CrossRef]

62. Pavlova, S.; Kilic, A.; Kilic, S.; So, J.; Nader-Macias, M.; Simoes, J.; Tao, L. Genetic diversity of vaginal lactobacilli from women in different countries based on $16 \mathrm{~S}$ rRNA gene sequences. J. Appl. Microbiol. 2002, 92, 451-459. [CrossRef] [PubMed]

63. Martínez, N.; Hidalgo-Cantabrana, C.; Delgado, S.; Margolles, A.; Sánchez, B. Filling the gap between collection, transport and storage of the human gut microbiota. Sci. Rep. 2019, 9, 8327. [CrossRef] [PubMed]

64. Cribby, S.; Taylor, M.; Reid, G. Vaginal Microbiota and the Use of Probiotics. Interdiscip. Perspect. Infect. Dis. 2008, 2008, 256490. [CrossRef] [PubMed]

65. Khodaverdi, S.; Khodaverdi, R.; Khaledi, M.; Mesdaghinia, L.; Sharifzadeh, F.; Nasiripour, S.; Gorginzadeh, M. Beneficial Effects of Oral Lactobacillus on Pain Severity in Women Suffering from Endometriosis: A Pilot Placebo-Controlled Randomized Clinical Trial. Int. J. Fertil. Steril. 2019, 13, 178-183. [CrossRef]

66. Itoh, H.; Sashihara, T.; Hosono, A.; Kaminogawa, S.; Uchida, M. Lactobacillus gasseri OLL2809 inhibits development of ectopic endometrial cell in peritoneal cavity via activation of NK cells in a murine endometriosis model. Cytotechnology 2011, 63, 205-210. [CrossRef]

67. Sashihara, T.; Sueki, N.; Ikegami, S. An analysis of the effectiveness of heat-killed lactic acid bacteria in alleviating allergic diseases. J. Dairy Sci. 2006, 89, 2846-2855. [CrossRef]

68. Sashihara, T.; Sueki, N.; Furuichi, K.; Ikegami, S. Effect of growth conditions of Lactobacillus gasseri OLL2809 on the immunostimulatory activity for production of interleukin-12 (p70) by murine splenocytes. Int. J. Food Microbiol. 2007, 120, 274-281. [CrossRef]

69. Qin, C.; Xu, L.; Yang, Y.; He, S.; Dai, Y.; Zhao, H.; Zhou, Z. Comparison of fecundity and offspring immunity in zebrafish fed Lactobacillus rhamnosus CICC 6141 and Lactobacillus casei BL23. Reproduction 2013, 147, $53-64$. [CrossRef]

70. Zhou, Z.; Wang, W.; Liu, W.; Gatlin, D.; Zhang, Y.; Yao, B.; Ringø, E. Identification of highly-adhesive gut Lactobacillus strains in zebrafish (Danio rerio) by partial rpoB gene sequence analysis. Aquaculture 2012, 370 , 150-157. [CrossRef]

71. Treven, P.; Mrak, V.; Bogovič-Matijašić, B.; Horvat, S.; Rogelj, I. Administration of probiotics Lactobacillus rhamnosus GG and Lactobacillus gasseri K7 during pregnancy and lactation changes mouse mesenteric lymph nodes and mammary gland microbiota. J. Dairy Sci. 2015, 98, 2114-2128. [CrossRef]

72. Schultz, M.; Göttl, C.; Young, R.J.; Iwen, P.; Vanderhoof, J.A. Administration of oral probiotic bacteria to pregnant women causes temporary infantile colonisation. J. Pediatric Gastroenterol. Nutr. 2004, 38, $293-297$. [CrossRef] [PubMed]

73. Matijašić, B.B.; Obermajer, T.; Zorič Peternel, M.; Trachatova, S.; Spanova, A.; Rogelj, I. Detection of the Lactobacillus gasseri $\mathrm{K} 7$ probiotic strain in feces and in human milk with molecular methods. Med. Razgl. 2009, 48, 137-138.

74. Gaggìa, F.; Mattarelli, P.; Biavati, B. Probiotics and prebiotics in animal feeding for safe food production. Int. J. Food Microbiol. 2010, 141, S15-S28. [CrossRef] [PubMed]

75. Jeżewska-Frąckowiak, J.; Seroczyńska, K.; Banaszczyk, J.; Jedrzejczak, G.; Żylicz-Stachula, A.; Skowron, P.M. The promises and risks of probiotic Bacillus species. Acta Biochim. Pol. 2018, 65, 509-519. [CrossRef]

76. Medina, M.; De Palma, G.; Ribes-Koninckx, C.; Calabuig, M.; Sanz, Y. Bifidobacterium strains suppress in vitro the pro-inflammatory milieu triggered by the large intestinal microbiota of coeliac patients. J. Inflamm. Res. 2008, 5, 19. [CrossRef]

77. Jang, S.; Jeong, J.; Choi, S.; Kim, H.; Han, M.; Kim, D. Lactobacillus rhamnosus HN001 and Lactobacillus acidophilus La-14 Attenuate Gardnerella vaginalis-Infected Bacterial Vaginosis in Mice. Nutrients 2017, 9, 531. [CrossRef]

78. Doron, S.; Snydman, D. Risk and Safety of Probiotics. Clin. Infect. Dis. 2015, 60, S129-S134. [CrossRef]

79. Di Pierro, F.; Polzonetti, V.; Patrone, V.; Morelli, L. Microbiological Assessment of the Quality of Some Commercial Products Marketed as Lactobacillus crispatus-Containing Probiotic Dietary Supplements. Microorganisms 2019, 7, 524. [CrossRef] 
80. Ricci, A.; Allende, A.; Bolton, D.; Chemaly, M.; Davies, R.; Girones, R.; Herman, L.; Koutsoumanis, K.; Lindavist, R.; Norrung, B.; et al. Scientific Opinion on the update of the list of QPS-recommended biological agents intentionally added to food or feed as notified to EFSA. EFSA J. 2017, 15, e04664.

81. Food and Agriculture Organization/World Health Organization. Guidelines for the Evaluation of Probiotics in Food; Food and Agriculture Organization of the United Nations/World Health Organization: London, UK, 2002.

(C) 2020 by the authors. Licensee MDPI, Basel, Switzerland. This article is an open access article distributed under the terms and conditions of the Creative Commons Attribution (CC BY) license (http://creativecommons.org/licenses/by/4.0/). 